\title{
Catheter ablation for atrial fibrillation
}

\author{
Steven A Lubitz, Avi Fischer, Valentin Fuster
}

\section{PRACTICE p 830}

Zena and Michael A Wiener Cardiovascular Institute, MarieJosee and Henry R Kravis Center for Cardiovascular Health, Mount Sinai School of Medicine,

Box 1030, New York, NY 10029, USA

Correspondence to: S A Lubitz

steven.lubitz@mssm.edu

BMJ 2008;336:819-26

doi:10.1136/bmj.39513.555150.BE

Sources and selection criteria

We searched all entries in PubMed through

September 2007 with the medical subject

headings "atrial

fibrillation", "catheter

ablation", and "anti-

arrhythmia agents". We

reviewed the reference

lists of retrieved articles

to identify any additional

relevant articles for

inclusion. Whenever

available, we chose

randomised controlled

trials and meta-analyses

over prospective cohort

studies. When these

were not available, we

cited retrospective

studies. We included

other references if judged

relevant for the purposes

of discussion. Thus this

work is not an exhaustive review but represents an overview of current clinical and technical aspects pertaining to catheter ablation of atrial fibrillation.
Atrial fibrillation is the most common arrhythmia in clinical practice and is associated with significant morbidity and mortality. ${ }^{1}$ Catheter ablation is increasingly being used to treat atrial fibrillation, although it is not suitable for all patients. ${ }^{2}$ Referring doctors must confront challenges such as the appropriate selection of patients for ablation and proper management of patients after the procedure, and must be familiar with the expected outcomes. Many unanswered questions exist surrounding the appropriate application of this technique.

This review summarises current ablative techniques and emphasises the appropriate application and limitations of catheter ablation on the basis of recent clinical trials and guidelines.

\section{What is catheter ablation of atrial fibrillation?}

After the transvenous insertion of catheters into the right atrium, the left atrium is accessed (in the absence of an atrial septal defect or patent foramen ovale) by trans-septal puncture. Catheter positioning, as well as the anatomy of the pulmonary veins and left atrium, are confirmed by fluoroscopy, pulmonary venography, three dimensional electroanatomical mapping, intracardiac echocardiography, computed tomography, remote guidance using magnetic resonance imaging, or combinations of these techniques. Through the application of thermal energy - most commonly by radiofrequency or cryothermy - injury is induced to the myocardium. Ablation can be done in atrial fibrillation or sinus rhythm.

\section{How have catheter ablation techniques evolved?}

The underlying factors contributing to atrial fibrillation are complex and multifactorial (fig 1). Current catheter ablation techniques target susceptible atrial substrate, electrical triggers, and autonomic tone, factors that are considered to be important for the initiation and maintenance of atrial fibrillation (box 1). Structural and electrical properties of the atria, such as fibrosis of the atrial myocardium, electromechanical remodelling, and genetic mutations affecting ion channels and gap junction proteins, are critical factors in the genesis of atrial fibrillation. Initial success with attempts to stop atrial fibrillation by creating linear incisions in the atria, as in the surgical Cox-Maze procedure, and replication of these lesions with radiofrequency catheter ablation, supported the concept of susceptible atrial substrate, although the contribution of pulmonary vein isolation was probably overlooked with these early techniques.

Ectopic pulmonary vein foci that communicate with the left atrium through muscular sleeves ${ }^{3}$ (figs 2 and 3 ) were later discovered to trigger atrial fibrillation in most patients, ${ }^{4}$ leading to targeted ablation within the pulmonary veins. As a result of pulmonary vein stenosis often associated with this procedure, techniques emerged that attempted to isolate the left atrium from the pulmonary veins. Predominant approaches included segmental ostial ablation at sites where pulmonary vein signals were detected, ${ }^{5}$ and anatomically guided circumferential pulmonary vein ablation encircling individual or ipsilateral pairs of pulmonary veins (fig 4). ${ }^{6}$

Recently, ablation of ganglionated plexi innervating the pulmonary veins and left atrium has emerged with recognition that autonomic tone contributes to the genesis of atrial fibrillation. ${ }^{78}$ Additionally, targeting complex fractionated electrograms-signals with rapid deflections and short cycle lengths corresponding to areas of wavebreak, vagal innervation, slow conduction, or re-entry-has become increasingly successful. ${ }^{910}$

The evolution of ablation techniques was illustrated in a survey of centres carrying out atrial fibrillation ablation worldwide between 1995 and 2002. ${ }^{2}$ In 1995, isolation of pulmonary veins was not reported by any of the centres. Between 1998 and 1999, after elucidation of the role of pulmonary vein triggers in the genesis of

Box 1: Targets of current ablation techniques

- Electrical triggers (pulmonary vein foci, non-pulmonary vein foci, supraventricular tachyarrhythmias, accessory pathways)

- Susceptible atrial substrate (caused by, for example, fibrosis, hypertrophy, mutations of ion or gap junctions, electromechanical remodelling from previous atrial fibrillation*)

- Autonomic innervation

*Cellular electrical and structural remodelling occur as a result of previous atrial fibrillation, predisposing to subsequent episodes of atrial fibrillation 


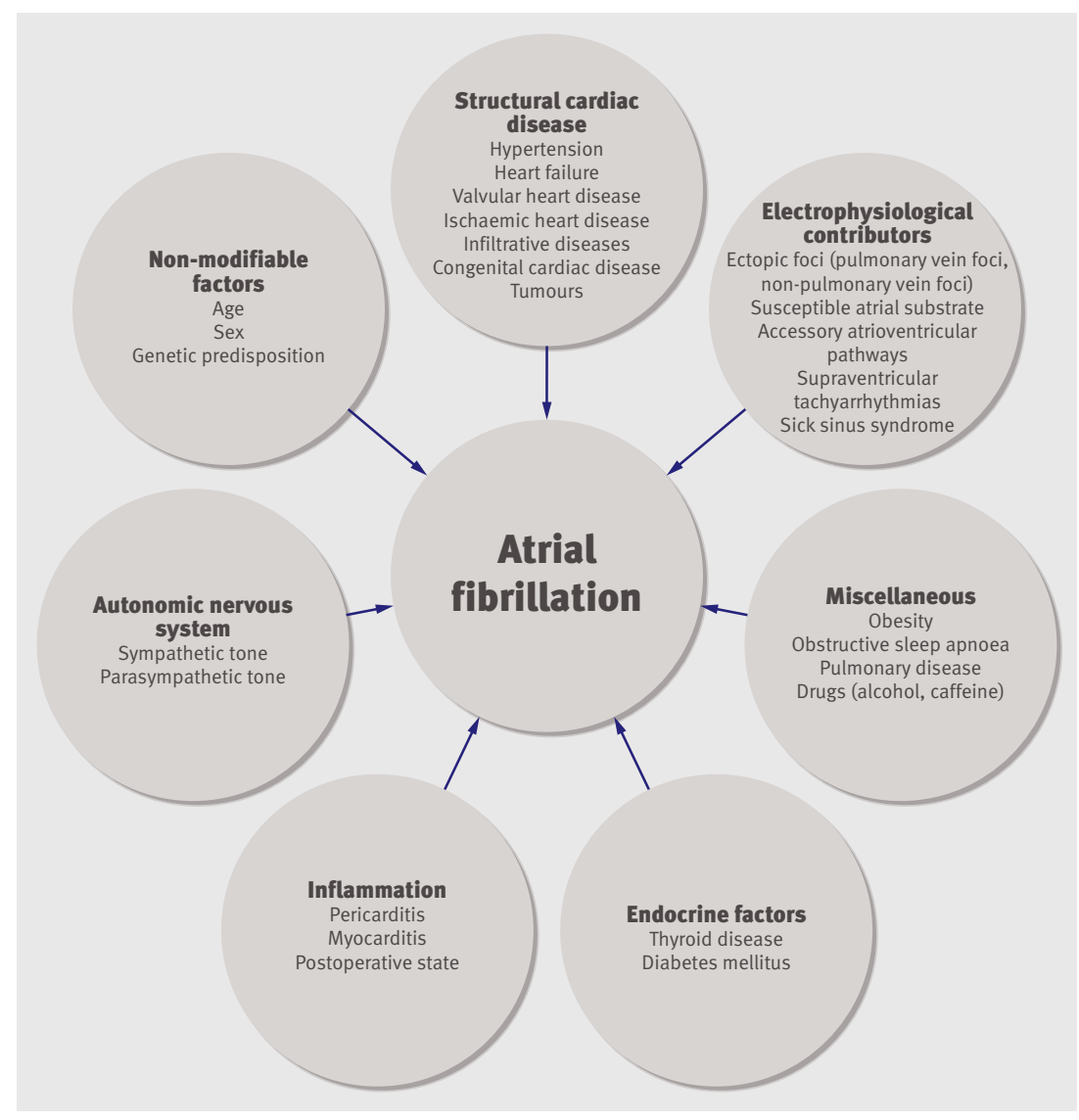

Fig 1 | Factors contributing to development of atrial fibrillation. Clinical factors predisposing patients to atrial fibrillation are complex and may be inter-related. ${ }^{*}$ These conditions may result in structural changes such as left atrial enlargement or stretch, myocardial hypertrophy, or left ventricular systolic dysfunction and are often treated with cardioversion, antiarrhythmic drugs, and repeat ablation.

Initial reports described success rates between $22 \%$ and $85 \%$, with better results observed for patients with paroxysmal (self terminating and lasting less than seven days) rather than persistent (not self terminating) or permanent atrial fibrillation (terminating attempts failed or were not attempted). Randomised trials comparing pulmonary vein isolation in symptomatic patients, most with paroxysmal disease, reported success rates ranging from $31 \%$ to $88 \%$, with no clearly superior strategy (table 1). ${ }^{14-18}$ Long term results are limited by follow-up of generally no more than one year in most trials. Outcomes may have been influenced by the different patient populations studied, ablative techniques and end points utilised, and number of repeat ablations.

Moreover, substantially different methods for surveillance of rhythm were used, such as 12 lead electrocardiography, Holter monitoring, or event monitoring as prompted by symptoms. These methods have varying diagnostic accuracy for detecting occult arrhythmias. As few studies reported the incidence of recurrent asymptomatic atrial fibrillation after ablation, the benefits may have been overestimated. Available data show that asymptomatic recurrences occur in $2 \%$ to $16 \%$ of patients within the first year of the procedure (table 1), ${ }^{151618}$ although recurrences were prevalent in only $2 \%$ of patients with paroxysmal atrial fibrillation two years after ablation in one single centre analysis. ${ }^{19}$

A consensus statement by the Heart Rhythm Society, European Heart Rhythm Association, and European Cardiac Arrhythmia Society states that patients should be evaluated with electrocardiography within three months of ablation, every six months for the next two years, and assessed with event monitors if they have recurrent palpitations (box 2). ${ }^{20}$ These are similar to recommendations made by the Venice Chart international consensus group. ${ }^{22}$ The benefits of more extensive surveillance after ablation are unclear.

\section{Which ablation technique is most efficacious?}

Heterogeneity in the methods of published trials limits the ability to compare different techniques (table 1). A recent meta-analysis concluded that substrate ablation without pulmonary vein isolation was associated with no atrial fibrillation in $75 \%$ of patients at six months, whereas circumferential pulmonary vein isolation was successful in $67 \% .{ }^{23}$ Substrate ablation seems more important with persistent or permanent atrial fibrillation than with paroxysmal disease, where isolation of triggers may suffice. None the less, a consensus statement by electrophysiological societies in the United States and Europe recognises that electrical pulmonary vein isolation forms the basis of most successful catheter ablations (box 2). ${ }^{20}$ The ideal approach depends on individual patient characteristics and the chronicity of atrial fibrillation, and may require a combination of strategies (fig 5). 


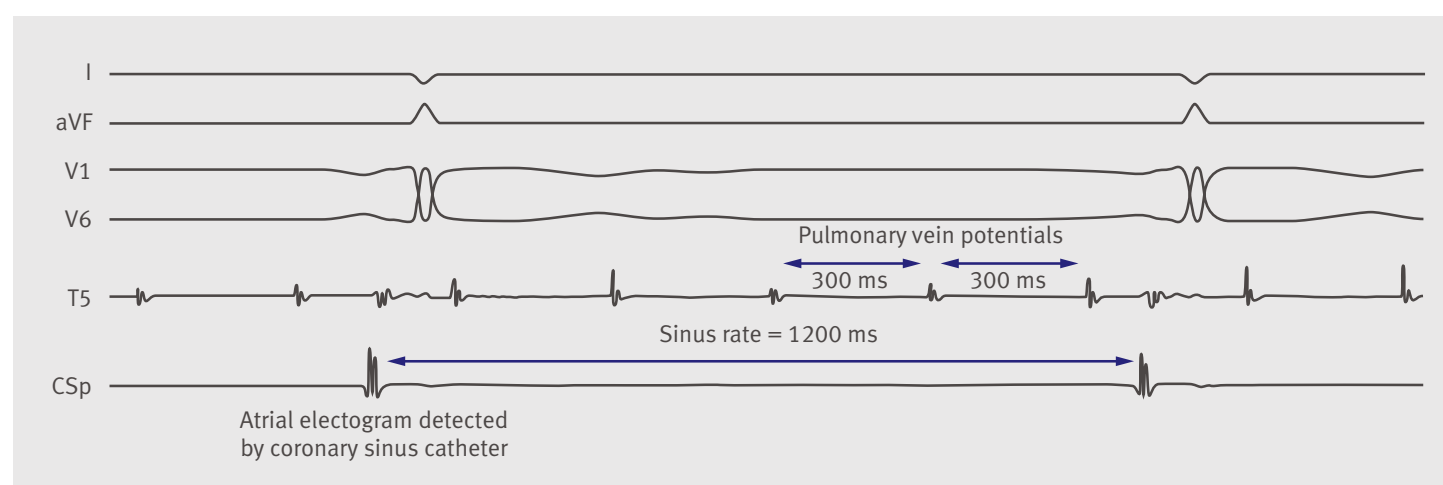

Fig 2 Intracardiac electrogram (recorded at a paper speed of $100 \mathrm{~mm} / \mathrm{s}$ ) from a patient with paroxysmal atrial fibrillation undergoing pulmonary vein isolation. Patient is in sinus rhythm at $50 \mathrm{bpm}$ (cycle length=1200 ms), seen on surface electrograms (I, aVF, V1, V6). An intracardiac atrial electrogram is detected at the same cycle length by a catheter in the coronary sinus, preceding the surface electrogram deflection. A circular lasso catheter in the left upper pulmonary vein (T5) records pulmonary vein potentials occurring at a cycle length of $300 \mathrm{~ms}$ and dissociated from sinus activity. Other measurement points from lasso catheter were removed for simplicity

\section{Is catheter ablation superior to medical therapy?}

Although a strategy for rhythm control with antiarrhythmic drugs or electrical cardioversion offers no survival advantage over a rate control strategy, retrospective analyses of major trials show that maintenance of sinus rhythm may be associated with improved survival ${ }^{24}$ and quality of life. ${ }^{25}$ In the atrial fibrillation follow-up investigation of rhythm management (AFFIRM) trial, non-cardiovascular deaths in the rhythm control arm exceeded those in the rate control arm, ${ }^{26}$ fuelling speculation that adverse effects of antiarrhythmic drugs may obscure the benefits of maintaining sinus rhythm and justifying the comparison of catheter ablation with medical therapy for achievement of sinus rhythm.

In a pilot trial of 70 patients with predominantly paroxysmal atrial fibrillation, pulmonary vein isolation was compared with antiarrhythmic drugs as first line therapy (table 2). ${ }^{27}$ Freedom from symptomatic atrial fibrillation at one year after a single procedure was $87 \%$

\begin{tabular}{|c|c|c|c|c|c|c|c|c|c|c|c|}
\hline \multirow[b]{2}{*}{ Study } & \multirow[b]{2}{*}{ No } & \multirow{2}{*}{$\begin{array}{l}\text { Type of atrial } \\
\text { fibrillation } \\
\text { (\%) }\end{array}$} & \multirow{2}{*}{$\begin{array}{l}\text { Additional } \\
\text { substrate } \\
\text { ablation }\end{array}$} & \multirow{2}{*}{$\begin{array}{c}\text { Rhythm } \\
\text { monitoring* }\end{array}$} & \multirow{2}{*}{$\begin{array}{r}\text { Follow-up } \\
\text { (months) }\end{array}$} & \multicolumn{2}{|c|}{$\begin{array}{l}\text { Freedom from } \\
\text { recurrent atrial } \\
\text { tachyarrhythmia } \\
(\%)\end{array}$} & \multicolumn{2}{|c|}{$\begin{array}{l}\text { Patients } \\
\text { requiring } \\
\text { repeat } \\
\text { ablations for } \\
\text { quoted } \\
\text { success rate } \\
(\%)\end{array}$} & \multirow[t]{2}{*}{$\begin{array}{c}\text { Overall } \\
\text { frequency of } \\
\text { asymptomatic } \\
\text { atrial } \\
\text { tachyarrhyth- } \\
\text { mia after } \\
\text { ablation }\end{array}$} & \multirow{2}{*}{$\begin{array}{c}\text { Overall } \\
\text { frequency of } \\
\text { major } \\
\text { complica- } \\
\text { tions } †\end{array}$} \\
\hline & & & & & & CPVA & SOA & CPVA & SOA & & \\
\hline Oral et al $2003^{14}$ & 80 & $\begin{array}{l}\text { Paroxysmal } \\
(100)\end{array}$ & CPVA group & $\begin{array}{l}\text { Event monitoring if } \\
\text { symptomatic }\end{array}$ & 6 & 88 & 67 & 0 & 0 & NR & 0 \\
\hline $\begin{array}{l}\text { Karch et al } \\
2005^{15}\end{array}$ & 100 & $\begin{array}{l}\text { Paroxysmal (89), } \\
\text { persistent (11) }\end{array}$ & CPVA group & $\begin{array}{l}7 \text { day Holter } \\
\text { monitoring at } \\
6 \text { months }\end{array}$ & 6 & 42 & 66 & 24 & 16 & 16 & 13 \\
\hline $\begin{array}{l}\text { Nilsson et al } \\
2006^{16}\end{array}$ & 100 & $\begin{array}{l}\text { Paroxysmal (51), } \\
\text { persistent (49) }\end{array}$ & None & $\begin{array}{l}14 \text { day Holter } \\
\text { monitoring at } \\
3 \text { months, event } \\
\text { monitoring if } \\
\text { symptomatic }\end{array}$ & 12 & 57 & 31 & 74 & 74 & 2 & 4 \\
\hline Liu et al $2006^{17}$ & 110 & $\begin{array}{l}\text { Paroxysmal } \\
(100)\end{array}$ & $\begin{array}{l}\text { SOA group if } \\
\text { inducible or } \\
\text { residual atrial } \\
\text { fibrillation }\end{array}$ & $\begin{array}{l}\text { Periodic Holter } \\
\text { monitoring }\end{array}$ & 9 & 84 & 78 & 9 & 13 & NR & 7 \\
\hline $\begin{array}{l}\text { Arentz et al } \\
2007^{18}\end{array}$ & 110 & $\begin{array}{l}\text { Paroxysmal (61), } \\
\text { persistent (39) }\end{array}$ & None & $\begin{array}{l}\text { Periodic Holter } \\
\text { monitoring; further } \\
\text { monitoring guided } \\
\text { by symptoms }\end{array}$ & 15 & 67 & 49 & 0 & 0 & 5 & 2 \\
\hline
\end{tabular}




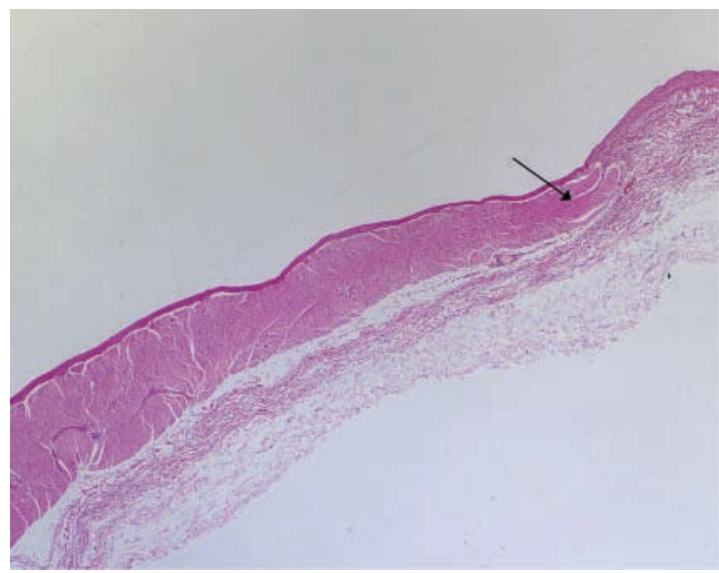

Fig 3 | Muscular sleeves extending into pulmonary vein. Specimen from pulmonary vein showing muscular sleeves (arrowhead) extending from left atrium into pulmonary vein. Haematoxylin and eosin, $\times 2$ magnification

compared with $37 \%$ for patients treated with antiarrhythmic drugs, most of whom received flecainide. In another study, pulmonary vein isolation in conjunction with antiarrhythmic drugs was compared with antiarrhythmic drugs alone in a group of 137 patients with mostly paroxysmal atrial fibrillation. ${ }^{28}$ Freedom from atrial arrhythmias at one year was 56\% in the ablation and antiarrhythmic drugs group and only $9 \%$ in the antiarrhythmic drugs alone group. More recently, pulmonary vein isolation was superior to a pharmacological strategy consisting of flecainide, sotalol, or amiodarone in a group of 198 patients with paroxysmal atrial fibrillation. ${ }^{29}$ Daily transtelephonic monitoring and periodic Holter monitoring showed that freedom from atrial tachyarrhythmias at one year was $86 \%$ in the ablation group and $22 \%$ in the antiarrhythmic drug group. The success of ablation improved to $93 \%$ when including second procedures. Two other randomised trials have reported results favouring ablation over medical therapy in patients with predominantly paroxysmal disease during one year of follow-up. ${ }^{3031}$ Catheter ablation specifically in persistent atrial fibrillation was addressed in a trial of 146 patients randomised to treatment with amiodarone and electrical cardioversion alone for up to three months, or in combination with pulmonary vein isolation. ${ }^{32}$ Freedom from atrial fibrillation or atrial flutter one year after ablation was $74 \%$ in the absence of antiarrhythmic drugs, including repeat ablations in $32 \%$ of patients. In the intention to treat analysis, $58 \%$ of patients in the control arm were free of atrial fibrillation, although $77 \%$ crossed over to the ablation arm.

These trials also reported that ablation improves symptoms or quality of life, ${ }^{2730-32}$ enhances ejection fraction, ${ }^{32}$ reduces left atrial size, ${ }^{2932}$ and decreases hospital admissions. ${ }^{2729}$ One non-randomised trial reported improved survival with ablation. ${ }^{33}$

Although traditional strategies for rhythm control do not seem to be cost effective when compared with rate control strategies for the management of atrial fibrillation, ${ }^{34}$ a recent decision analysis comparing rate control, rhythm control with antiarrhythmic drugs, and catheter ablation in cohorts of patients aged 55 and 65 years, concluded that ablation is cost effective for patients at moderate risk of stroke but not at low risk. ${ }^{35} \mathrm{~A}$ cost comparison of ablation and medical therapy using the Canadian Registry of Atrial Fibrillation showed that ablation was initially more expensive than medical therapy, although it was equivalent in cost about four years after ablation, justifying ablation as a "fiscally sensible alternative." 36

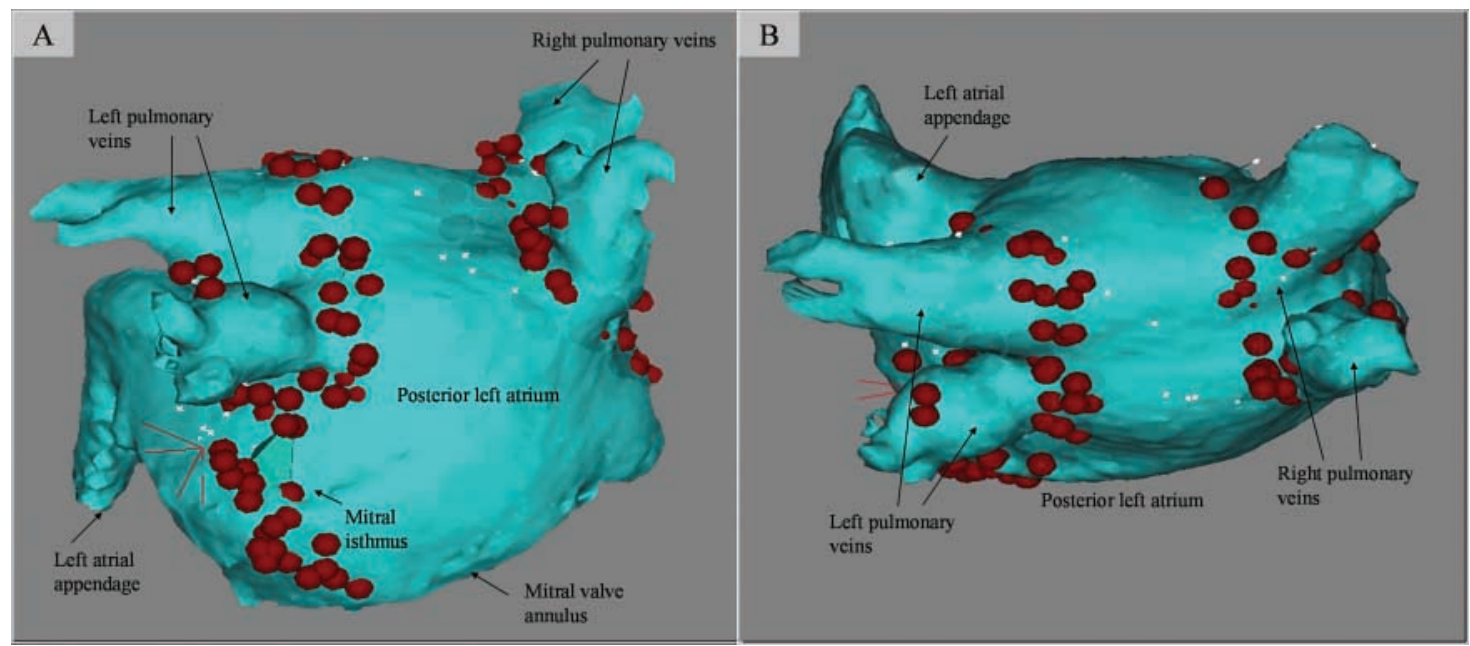

Fig 4 | Electroanatomical map of left atrium in patient with persistent atrial fibrillation undergoing pulmonary vein isolation. Computed tomogram before ablation procedure is merged with three dimensional electroanatomical map of left atrium created during ablation. Left atrium is viewed from a posterior (panel A) and superior (panel B) orientation, with left atrium appendage on left. Dots represent sites of delivery of radiofrequency energy. Radiofrequency lesions encircle both left and right pulmonary veins, avoiding posterior wall of left atrium, and a line of radiofrequency ablation is seen along the mitral isthmus (region extending from left inferior pulmonary vein to mitral annulus) 
Ablation was associated with an initial cost ranging from \$C16278 (£8157; €16441; \$10661) to $\$ \mathrm{C} 21294$, with subsequent annual costs of \$C1597 to $\$ \mathrm{C} 2132$, whereas costs for medical therapy ranged from \$C4176 to \$C5060 annually. Caution must be used in interpreting this analysis considering the lack of long-term follow up to support the durable effectiveness of ablation.

In summary, evidence from several small trials suggests that isolation of the pulmonary vein is more efficacious than medical rhythm control therapy in select patients with highly symptomatic, drug refractory atrial fibrillation, although long term outcomes remain unclear.

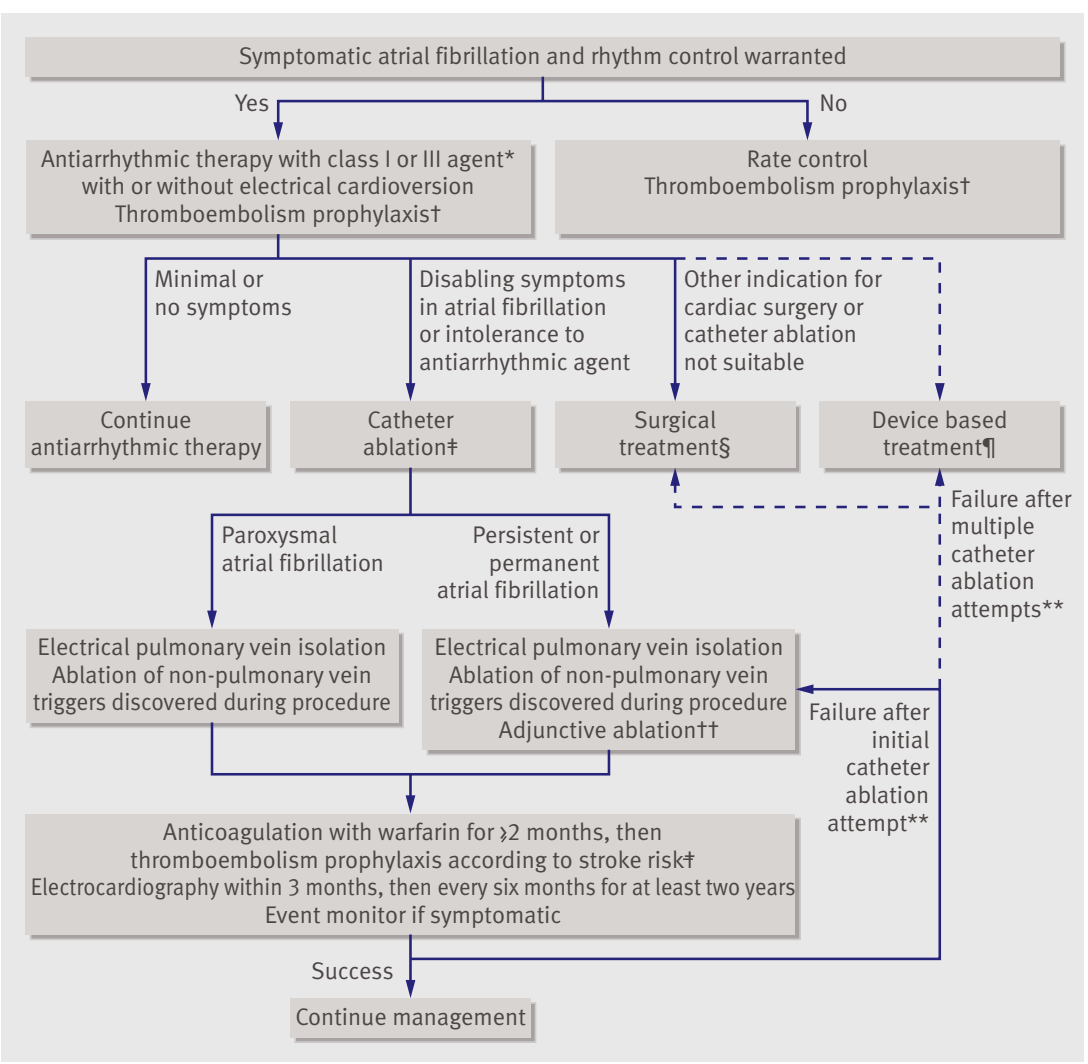

Fig 5 | Proposed algorithm for management of symptomatic patients with atrial fibrillation referred for rhythm control. Solid lines represent established pathways supported by clinical evidence, guidelines, or expert consensus documents. Dashed lines represent less established pathways. ${ }^{\star}$ Appropriate antiarrhythmic drug therapy is outlined in practice guidelines. ${ }^{1}+$ Underlying stroke risk can be assessed using the $\mathrm{CHADS}_{2}$ score ${ }^{21}$; one point each is assigned for a history of heart failure, hypertension, age $\mathbf{2 7 5}$, diabetes mellitus, and two points for previous cerebral ischaemia. Aspirin is generally recommended if the score is 0 , aspirin or warfarin if the score is 1 , and warfarin if the score is $\geq 2 .{ }^{1} \neq$ First line therapy with catheter ablation may be appropriate for patients in whom long term antiarrhythmic drug therapy may be harmful or for those who want to avoid antiarrhythmic drugs. Presence of a left atrial thrombus is an absolute contraindication to catheter ablation. §Summary of surgical techniques for restoration of atrial fibrillation can be found in Heart Rhythm Society consensus document. ${ }^{20}$ शPotential measures include permanent pacing or implantable atrial defibrillators for restoration of sinus rhythm. ${ }^{1 * *}$ Repeat catheter ablations should generally be delayed until at least three months after the initial procedure. No consensus exists on what constitutes the maximum number for repeat attempts. ††Substrate ablation in form of linear ablation, or ablation of complex fractionated electrograms or sites of autonomic innervation. Adjunctive ablation may be appropriate in patients with paroxysmal atrial fibrillation in whom an initial attempt has been unsuccessful
Box 2: Summary of a recent consensus statement on catheter ablation of atrial fibrillation*

\section{Indications}

Symptomatic atrial fibrillation refractory or intolerant to at least one class I or III antiarrhythmic drug

First line therapy for atrial fibrillation in rare clinical situations

Selected symptomatic patients with heart failure or reduced ejection fraction

\section{Contraindications}

Presence of a left atrial thrombus

\section{Technique}

Electrical isolation of pulmonary veins is the cornerstone of most atrial fibrillation ablation procedures

Non-pulmonary venous triggers should be ablated if discovered during the ablation procedure

Ablation of the cavotricuspid isthmus is indicated in patients with typical or isthmus dependent atrial flutter

Thromboembolism prophylaxis after ablation

Warfarin is recommended for at least two months after ablation

Further thromboembolism prophylaxis should be based on a patient's underlying risk for stroket

\section{Minimal surveillance and monitoring after ablation}

Patients should be assessed with electrocardiography within three months of ablation, and then every six months for at least two years

Patients with palpitations should be evaluated with an event monitor

\section{Repeat procedures}

Owing to frequent and often transient early atrial tachyarrhythmias after ablation, repeat procedures should be delayed for at least three months, during which time antiarrhythmic drug therapy is appropriate for relief of symptoms

*Adapted from an expert consensus statement by Heart Rhythm Society, European Heart Rhythm Association, and European Cardiac Arrhythmia Society ${ }^{20}$

†Underlying risk can be assessed using the $\mathrm{CHADS}_{2}$ score $^{21}$

\section{Is catheter ablation safe?}

The most undesirable complications of ablation are atrio-oesophageal fistulae, pulmonary vein stenosis, cardiac tamponade, stroke, and phrenic nerve injury (box 3 and tables 1 and 2). In a randomised trial comparing pulmonary vein isolation techniques, the incidence of pulmonary vein stenosis was $9 \%$, and cerebrovascular events occurred in up to $6 \%$ of patients. ${ }^{15}$ In a worldwide survey of more than 7000 patients, major complications were reported in $6 \%{ }^{2}$ These included periprocedural death $(0.05 \%)$, cardiac tamponade $(1.2 \%)$, stroke or transient ischaemic attack $(0.9 \%)$, and pulmonary vein stenosis $(1.6 \%)$. Although lower complication rates reported in many controlled trials are reassuring, procedures done outside of 
Table 2| Randomised controlled trials comparing efficacy of catheter ablation versus medical therapy for prevention of recurrent atrial fibrillation

\begin{tabular}{|c|c|c|c|c|c|c|c|c|c|c|c|}
\hline \multirow[b]{2}{*}{ Study } & \multirow[b]{2}{*}{ No } & \multirow{2}{*}{$\begin{array}{c}\text { Single or } \\
\text { multicentre } \\
\text { trial }\end{array}$} & \multirow{2}{*}{$\begin{array}{l}\text { Pulmonary vein } \\
\text { isolation } \\
\text { technique }\end{array}$} & \multirow{2}{*}{$\begin{array}{c}\text { Primary control } \\
\text { group therapy } \\
(\%)\end{array}$} & \multirow{2}{*}{$\begin{array}{l}\text { Type of atrial } \\
\text { fibrillation } \\
\text { (\%) }\end{array}$} & \multirow{2}{*}{$\begin{array}{l}\text { Ablation as } \\
\text { first line } \\
\text { therapy? }\end{array}$} & \multirow{2}{*}{$\begin{array}{l}\text { Rhythm } \\
\text { monitoring* }\end{array}$} & \multirow{2}{*}{$\begin{array}{l}\text { Follow- } \\
\text { up } \\
\text { (years) }\end{array}$} & \multicolumn{2}{|c|}{$\begin{array}{l}\text { Freedom from } \\
\text { recurrent atrial } \\
\text { tachyarrhythmia }\end{array}$} & \multirow{2}{*}{$\begin{array}{c}\text { Overall frequency } \\
\text { of major } \\
\text { complications } \\
\text { with ablation (\%)† }\end{array}$} \\
\hline & & & & & & & & & Ablation & Medical & \\
\hline $\begin{array}{l}\text { Krittayaphong } \\
\text { et al } 2003^{31}\end{array}$ & 30 & Single & SOA & $\begin{array}{l}\text { Amiodarone } \\
(100)\end{array}$ & $\begin{array}{l}\text { Paroxysmal } \\
(70), \\
\text { persistent (30) }\end{array}$ & No & $\begin{array}{l}\text { Periodic Holter } \\
\text { monitoring }\end{array}$ & 1 & 79 & 40 & 7 \\
\hline $\begin{array}{l}\text { Wazni et al } \\
2005^{27}\end{array}$ & 70 & Multicentre & SOA & $\begin{array}{l}\text { Flecainide (77), } \\
\text { sotalol (23) }\end{array}$ & $\begin{array}{l}\text { Paroxysmal } \\
(96), \\
\text { persistent (4) }\end{array}$ & Yes & $\begin{array}{l}\text { Daily brief event } \\
\text { monitoring } \\
\text { during first and } \\
\text { third months, } \\
\text { and periodic } \\
\text { Holter } \\
\text { monitoring }\end{array}$ & 1 & 87 & 37 & 3 \\
\hline $\begin{array}{l}\text { Oral et al } \\
2006^{32}\end{array}$ & 146 & Multicentre & CPVA & $\begin{array}{l}\text { Amiodarone and } \\
\text { up to two } \\
\text { electrical } \\
\text { cardioversions } \\
\text { within three } \\
\text { months of } \\
\text { randomisation }\end{array}$ & $\begin{array}{l}\text { Persistent or } \\
\text { permanent } \\
(100)\end{array}$ & No & $\begin{array}{l}\text { Daily brief event } \\
\text { monitoring }\end{array}$ & 1 & 74 & 58 & 0 \\
\hline $\begin{array}{l}\text { Stabile et al } \\
2006^{28} \ddagger\end{array}$ & 137 & Multicentre & CPVA & $\begin{array}{l}\text { Amiodarone } \\
(62) \text {, flecainide } \\
\text { (26), } \\
\text { propafenone } \\
\text { (10), } \\
\text { disopyramide } \\
\text { (2), sotalol (6)§ }\end{array}$ & $\begin{array}{l}\text { Paroxysmal } \\
(67), \\
\text { persistent (33) }\end{array}$ & No & $\begin{array}{l}\text { Daily brief event } \\
\text { monitoring } \\
\text { during first three } \\
\text { months, and } \\
\text { periodic Holter } \\
\text { monitoring }\end{array}$ & 1 & 56 & 9 & 4 \\
\hline $\begin{array}{l}\text { Pappone et al } \\
2006^{29}\end{array}$ & 198 & Single & CPVA & $\begin{array}{l}\text { Amiodarone } \\
\text { (33), flecainide } \\
\text { (33), sotalol } \\
\text { (33)§ }\end{array}$ & $\begin{array}{l}\text { Paroxysmal } \\
(100)\end{array}$ & No & $\begin{array}{l}\text { Daily brief event } \\
\text { monitoring, and } \\
\text { periodic Holter } \\
\text { monitoring }\end{array}$ & 1 & 86 & 22 & 1 \\
\hline $\begin{array}{l}\text { Jais et al } \\
2006^{30}\end{array}$ & 112 & Multicentre & SOA & §ণ & $\begin{array}{l}\text { Paroxysmal } \\
\text { (100) }\end{array}$ & No & $\begin{array}{l}\text { Periodic Holter } \\
\text { monitoring }\end{array}$ & 1 & 75 & 6 & 4 \\
\hline
\end{tabular}

CPVA=circumferential pulmonary vein ablation; SOA=segmental ostial ablation.

*Includes assessment at routine clinic appointments.

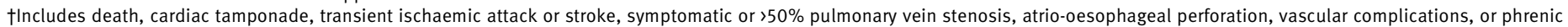
nerve injury.

$\ddagger$ According to study protocol, patients treated with catheter ablation also received antiarrhythmic drug therapy.

$\S$ Various combinations of antiarrhythmic drugs were used.

INot specified but 88 class I, 39 class II, 59 class III, and 6 class IV agents were used.

clinical trials and by less experienced operators might result in more adverse effects.

\section{Is thromboembolism prophylaxis necessary after ablation?}

In most trials of ablation, anticoagulation was stopped after three to six months in the absence of recurrent atrial fibrillation without any significant incidence of thromboembolism during follow-up. The baseline risk for stroke as measured by validated tools such as the $\mathrm{CHADS}_{2}$ index, ${ }^{21}$ was not, however, reported. In a retrospective analysis of 755 patients, $65 \%$ of whom had paroxysmal atrial fibrillation, the incidence of thromboembolism was $0.9 \%$ within the two weeks after ablation, and $0.2 \%$ between six and 10 months afterwards. ${ }^{37}$ None of the patients in whom anticoagulation was discontinued had a stroke, including about half of whom had at least one risk factor.

Recent guidelines call for mandatory warfarin therapy for at least two months after ablation (box 2), ${ }^{20}$ although clinical trials have not specifically assessed the optimal antithrombotic strategy. Until further data confirm the reduced stroke risk and ensure the absence of recurrent atrial fibrillation in a large and heterogeneous population, patients should continue to receive thromboembolism prophylaxis on the basis of their initial stroke risk in accordance with published guidelines. ${ }^{120}$

\section{Ongoing research}

The catheter ablation versus antiarrhythmic drug therapy for atrial fibrillation (CABANA) trial will assess survival outcomes among patients treated with ablation compared with those treated with pharmacological rhythm or rate control

The multicenter radiofrequency ablation versus antiarrhythmic drugs for atrial fibrillation treatment (RAAFT) trial will compare catheter ablation as first line therapy against antiarrhythmic drugs

The catheter ablation for the cure of atrial fibrillation (CACAF-2) study will compare the efficacy of catheter ablation with combined right and left atrial lesions against antiarrhythmic drugs in patients with persistent atrial fibrillation refractory to at least one antiarrhythmic drug 
Box 3: Potential major complications of catheter ablation of atrial fibrillation

- Periprocedural death

- Cardiac tamponade

- Thromboembolism, including stroke or transient ischaemic attack

- Air embolism

- Atrio-oesophageal fistula

- Pulmonary vein stenosis

- Phrenic nerve injury

- Perioesophageal vagal nerve injury

- Vascular complications (haematoma, pseudoaneurysm, arteriovenous fistula, retroperitoneal bleeding)

- Acute coronary artery occlusion

- Mitral valve trauma

\section{Additional educational resources}

American College of Cardiology (www.acc.org)— 2006 guidelines for the management of patients with atrial fibrillation from the American College of Cardiology, the American Heart Association, and the European Society of Cardiology

Heart Rhythm Society (www.hrsonline.org)—Expert consensus statement on catheter and surgical ablation of atrial fibrillation from the Heart Rhythm Society, European Heart Rhythm Association, and European Cardiac Arrhythmia Society

Natale A, Raviele A, Arentz T, Calkins H, Chen SA, Haissaguerre M, et al. Venice Chart international consensus document on atrial fibrillation ablation. J Cardiovasc Electrophysiol 2007;18:560-80.

\section{Information for patients}

MedlinePlus (www.nlm.nih.gov/medlineplus/ healthtopics.html)-Online patient information resource from the United States National Library of Medicine and National Institutes of Health

American Heart Association (www.americanheart.org/) and Heart Rhythm Society (www.hrsonline.org)—Both contain resources for patients

\section{Conclusion}

Rhythm control of atrial fibrillation is receiving a resurgence of attention with the recognition that catheter ablation may offer benefits not achieved with pharmacological therapy. At present, patients considering ablation must be willing to undergo a prolonged procedure with associated risks, and a significant likelihood of recurrent disease that may necessitate a repeat ablation. As the understanding of mechanisms of atrial fibrillation evolves, catheter ablation techniques will follow suit. Large scale controlled trials assessing ablation in diverse patient populations are necessary for more precise clinical guidelines for its application.

We thank Marc A Miller for his critical review of the manuscript. Figure 3 is courtesy of John Fallon.

Contributors: All authors planned and contributed to the writing of the manuscript. SAL is guarantor.

Competing interests: AF consults for and has received honorariums from Medtronic and receives research support from St Jude Medical. Provenance and peer review: Not commissioned; externally peer reviewed.

\section{Tips for non-specialists}

Patients should be considered for referral for atrial fibrillation ablation when rhythm control therapy is indicated and attempts with at least one antiarrhythmic drug have failed

A substantial proportion of patients may require repeat ablations owing to recurrences of atrial fibrillation or left atrial tachyarrhythmias resulting from the procedure itself Guidelines recommend anticoagulation with warfarin for at least two months after ablation, but the optimal strategy for thromboembolism prophylaxis has not been tested

Guidelines advocate electrocardiography within three months after ablation, and every six months thereafter, although the merits of more rigorous surveillance remain untested
1 Fuster V, Ryden LE, Cannom DS, Crijns HJ, Curtis AB, Ellenbogen KA, et al. ACC/AHA/ESC 2006 guidelines for the management of patients with atrial fibrillation: a report of the American College of Cardiology/ American Heart Association Task Force on Practice Guidelines and the European Society of Cardiology Committee for Practice Guidelines Writing Committee to revise the 2001 Guidelines for the Management of Patients With Atrial Fibrillation): developed in collaboration with the European Heart Rhythm Association and the Heart Rhythm Society. Circulation 2006;114:e257-354.

2 Cappato R, Calkins H, Chen SA, Davies W, lesaka Y, Kalman J, et al. Worldwide survey on the methods, efficacy, and safety of catheter ablation for human atrial fibrillation. Circulation 2005;111:1100-5.

3 Nathan $\mathrm{H}$, Eliakim $\mathrm{M}$. The junction between the left atrium and the pulmonary veins. An anatomic study of human hearts. Circulation 1966;34:412-22.

4 Haissaguerre M, Jais P, Shah DC, Takahashi A, Hocini M, Quiniou G, et al. Spontaneous initiation of atrial fibrillation by ectopic beats originating in the pulmonary veins. N Engl J Med 1998;339:659-66. 


\section{SUMMARY POINTS}

Atrial fibrillation is the most common arrhythmia in clinical practice

Common triggers are ectopic pulmonary venous foci which conduct to the left atrium

Catheter ablation techniques usually involve radiofrequency energy to electrically isolate the pulmonary veins from the left atrium

Ablation may be more successful in patients with paroxysmal atrial fibrillation rather than persistent atrial fibrillation

Atrial fibrillation ablation seems more successful than medical rhythm control therapy in carefully selected patients

Ablation is indicated in patients requiring rhythm control and who have failed with at least one antiarrhythmic drug

Long term data on the safety and efficacy of atrial fibrillation ablation are limited

5 Haissaguerre M, Shah DC, Jais P, Hocini M, Yamane T, Deisenhofer I, et al. Electrophysiological breakthroughs from the left atrium to the pulmonary veins. Circulation 2000;102:2463-5.

6 Pappone C, Rosanio S, Oreto G, Tocchi M, Gugliotta F, Vicedomini G, et al. Circumferential radiofrequency ablation of pulmonary vein ostia: a new anatomic approach for curing atrial fibrillation. Circulation 2000;102:2619-28.

7 Chen YJ, Chen SA, Tai CT, Wen ZC, Feng AN, Ding YA, et al. Role of atrial electrophysiology and autonomic nervous system in patients with supraventricular tachycardia and paroxysmal atrial fibrillation. J Am Coll Cardiol 1998;32:732-8.

8 Pappone C, Santinelli V, Manguso F, Vicedomini G, Gugliotta F, Augello $\mathrm{G}$, et al. Pulmonary vein denervation enhances long-term benefit after circumferential ablation for paroxysmal atrial fibrillation. Circulation 2004;109:327-34.

9 Nademanee K, McKenzie J, KosarE, Schwab M, Sunsaneewitayakul B, Vasavakul T, et al. A new approach for catheter ablation of atrial fibrillation: mapping of the electrophysiologic substrate. J Am Coll Cardiol 2004;43:2044-53.

10 Oral H, Chugh A, Good E, Sankaran S, Reich SS, Igic P, et al. A tailored approach to catheter ablation of paroxysmal atrial fibrillation. Circulation 2006;113:1824-31.

11 Oral H, Knight BP, Ozaydin M, Tada H, Chugh A, Hassan S, et al. Clinical significance of early recurrences of atrial fibrillation after pulmonary vein isolation. J Am Coll Cardiol 2002;40:100-4.

12 Bertaglia E, Stabile G, Senatore G, Zoppo F, Turco P, Amellone C, et al. Predictive value of early atrial tachyarrhythmias recurrence after circumferential anatomical pulmonary vein ablation. Pacing Clin Electrophysiol 2005;28:366-71.

13 Ouyang F, Antz M, Ernst S, Hachiya H, Mavrakis H, Deger FT, et al. Recovered pulmonary vein conduction as a dominant factor for recurrent atrial tachyarrhythmias after complete circular isolation of the pulmonary veins: lessons from double Lasso technique. Circulation 2005;111:127-35.

14 Oral H, Scharf C, Chugh A, Hall B, Cheung P, Good E, et al. Catheter ablation for paroxysmal atrial fibrillation: segmental pulmonary vein ostial ablation versus left atrial ablation. Circulation 2003;108:2355-60.

15 Karch MR, Zrenner B, Deisenhofer I, Schreieck J, Ndrepepa G, Dong J, et al. Freedom from atrial tachyarrhythmias after catheter ablation of atrial fibrillation: a randomized comparison between 2 current ablation strategies. Circulation 2005;111:2875-80.

16 Nilsson B, Chen X, Pehrson S, Kober L, Hilden J, Svendsen JH. Recurrence of pulmonary vein conduction and atrial fibrillation after pulmonary vein isolation for atrial fibrillation: a randomized trial of the ostial versus the extraostial ablation strategy. Am Heart J 2006;152:537 e1-8.

17 Liu X, Long D, Dong J, Hu F, Yu R, Tang R, et al. Is circumferential pulmonary vein isolation preferable to stepwise segmental pulmonary vein isolation for patients with paroxysmal atria fibrillation? Circ J 2006;70:1392-7.
18 Arentz T, Weber R, Burkle G, Herrera C, Blum T, Stockinger J, et al. Small or large isolation areas around the pulmonary veins for the treatment of atrial fibrillation? Results from a prospective randomized study. Circulation 2007;115:3057-63.

19 Oral H, Veerareddy S, Good E, Hall B, Cheung P, Tamirisa K, et al. Prevalence of asymptomatic recurrences of atrial fibrillation after successful radiofrequency catheter ablation. J Cardiovasc Electrophysiol 2004;15:920-4.

20 Calkins H, Brugada J, Packer DL, Cappato R, Chen S, Crijns HJ, et al. HRS/EHRA/ECAS Expert consensus statement on catheter and surgical ablation of atrial fibrillation: recommendations for personnel, policy, procedures and follow-up. A report of the Heart Rhythm Society (HRS) Task Force on catheter and surgical ablation of atrial fibrillation. Heart Rhythm 2007;4:816-61.

21 Gage BF, Waterman AD, Shannon W, Boechler M, Rich MW, Radford MJ.Validation of clinical classification schemes for predicting stroke: results from the National Registry of Atrial Fibrillation. JAMA 2001;285:2864-70.

22 Natale A, Raviele A, Arentz T, Calkins H, Chen SA, Haissaguerre M, et al. Venice Chart international consensus document on atrial fibrillation ablation. J Cardiovasc Electrophysiol 2007;18:560-80.

23 Fisher JD, Spinelli MA, Mookherjee D, Krumerman AK, Palma EC. Atria fibrillation ablation: reaching the mainstream. Pacing Clin Electrophysiol 2006;29:523-37.

24 Corley SD, Epstein AE, DiMarco JP, Domanski MJ, Geller N, Greene HL, et al. Relationships between sinus rhythm, treatment, and survival in the atrial fibrillation follow-up investigation of rhythm management (AFFIRM) study. Circulation 2004;109:1509-13.

25 Hagens VE, Ranchor AV, Van Sonderen E, Bosker HA, Kamp O, Tijssen JG, et al. Effect of rate or rhythm control on quality of life in persistent atrial fibrillation. Results from the rate control versus electrical cardioversion (RACE) study. J Am Coll Cardiol 2004;43:241-7.

26 Steinberg JS, Sadaniantz A, Kron J, Krahn A, Denny DM, Daubert J, et al. Analysis of cause-specific mortality in the atrial fibrillation follow-up investigation of rhythm management (AFFIRM) study. Circulation 2004;109:1973-80.

27 Wazni OM, Marrouche NF, Martin DO, Verma A, Bhargava M, Saliba W, et al. Radiofrequency ablation vs antiarrhythmic drugs as first-line treatment of symptomatic atrial fibrillation: a randomized trial. JAMA 2005;293:2634-40.

28 Stabile G, Bertaglia E, Senatore G, De Simone A, Zoppo F, Donnici G, et al. Catheter ablation treatment in patients with drug-refractory atrial fibrillation: a prospective, multi-centre, randomized, controlled study (catheter ablation for the cure of atrial fibrillation study). Eur Heart J 2006;27:216-21.

29 Pappone C, Augello G, Sala S, Gugliotta F, Vicedomini G, Gulletta S et al. A randomized trial of circumferential pulmonary vein ablation versus antiarrhythmic drug therapy in paroxysmal atrial fibrillation: the APAF study. J Am Coll Cardiol 2006;48:2340-7.

30 Jais P, Cauchemez B, Macle L, Daoud E, Waldo AL, Ruskin JN, et al. Atrial fibrillation ablation vs antiarrhythmic drugs: a multicenter randomized trial. Heart Rhythm 2006;3:1126.

31 Krittayaphong R, Raungrattanaamporn O, Bhuripanyo K, Sriratanasathavorn C, Pooranawattanakul S, Punlee K, et al. A randomized clinical trial of the efficacy of radiofrequency cathete ablation and amiodarone in the treatment of symptomatic atrial fibrillation. J Med Assoc Thai 2003;86(suppl 1):S8-16.

32 Oral H, Pappone C, Chugh A, Good E, Bogun F, Pelosi FJr, et al. Circumferential pulmonary-vein ablation for chronic atrial fibrillation. N Engl J Med 2006;354:934-41.

33 Pappone C, Rosanio S, Augello G, Gallus G, Vicedomini G, Mazzone P, et al. Mortality, morbidity, and quality of life after circumferential pulmonary vein ablation for atrial fibrillation: outcomes from a controlled nonrandomized long-term study. J Am Coll Cardiol 2003;42:185-97.

34 Marshall DA, Levy AR, Vidaillet H, Fenwick E, Slee A, Blackhouse G, et al. Cost-effectiveness of rhythm versus rate control in atrial fibrillation. Ann Intern Med 2004;141:653-61.

35 Chan PS, Vijan S, Morady F, Oral H. Cost-effectiveness of radiofrequency catheter ablation for atrial fibrillation.J Am Coll Cardiol 2006;47:2513-20.

36 Khaykin Y, Morillo CA, Skanes AC, McCracken A, Humphries K, Kerr CR. Cost comparison of catheter ablation and medical therapy in atrial fibrillation. J Cardiovasc Electrophysiol 2007;18:907-13.

37 Oral H, Chugh A, Ozaydin M, Good E, Fortino J, Sankaran S, et al. Risk of thromboembolic events after percutaneous left atrial radiofrequency ablation of atrial fibrillation. Circulation 2006;114:759-65.

38 Hsu LF, Jais P, Sanders P, Garrigue S, Hocini M, Sacher F, et al. Catheter ablation for atrial fibrillation in congestive heart failure. $N$ Engl $J$ Med 2004;351:2373-83. 